\title{
Del barrio a la ciudad. Nuevos roles ocupacionales y formas de sociabilidad de las mujeres populares en Cartagena, 1890-1954*
}

\section{From the Neighborhood to the City. New Occupational Roles and Forms of Sociability of Popular Women in Cartagena 1890-1954}

\author{
Raúl Cera Ochoa** \\ Universidad de Cartagena, Cartagena, Colombia
}

Recibido: 18 de enero de 2019. Aprobado: 19 de marzo de 2019.

DOI: 10.25100/lamanzanadeladiscordia.v14i1.8057

Artículo de investigación

\begin{abstract}
Resumen
Este artículo analiza las transformaciones en los roles de las mujeres populares urbanas de Cartagena entre 1890 y 1954. El autor reconstruye algunas dinámicas que configuraron a la ciudad en una sociedad moderna, como son la construcción y la habitación de espacios públicosnuevos barrios por fuera de las murallas-, dinámicas que hicieron evidentes problemas de crecimiento poblacional desordenado, planificación urbana, desigualdad y pobreza. No obstante, para estas mujeres como actores sociales habitar la ciudad significaba una oportunidad para acceder a beneficios, la posibilidad de ocuparse en oficios varios y mejorar su calidad de vida, la de sus familias y vecinos. Desde una perspectiva de género, esta reflexión introduce la historia de las mujeres en plural y la noción de la diferencia. Para ello, se revisaron fuentes primarias de la prensa comercial localizadas en archivos de Cartagena.
\end{abstract}

Palabras clave: roles; mujeres; género; historia; ciudad.

\begin{abstract}
This article analyzes the transformations in the roles of the urban popular women of Cartagena during 1890 and 1954. The author reconstructs some dynamics that shaped the city in a modern society. Dynamics such as the construction and the habitation of public spaces -new neighborhoods outside the walls- that made evident problems of disorderly population growth, urban planning, inequality and poverty. However, for these women as social actors, living in the city meant an opportunity to access benefits, the possibility of taking up various jobs and improving their quality of life, that of their families and neighbors. From a gender perspective, this reflection introduces the history of women in the plural and the notion of difference. To this end, primary sources of the commercial press located in Cartagena archives were reviewed.
\end{abstract}

Keywords: roles; women; gender; history; city.

* El artículo está vinculado al proyecto de grado de maestría titulado Prácticas de sociabilidad y organización política en Cartagena: representaciones en la prensa de las mujeres en los barrios populares de la ciudad, desde 1948 hasta 1954; ejecutado entre 2016 hasta 2017 gracias a fondos de la Universidad Andina Simón Bolívar, Quito, Ecuador. No obstante, la delimitación temporal propuesta en el artículo, obedece a que se revisaron fuentes secundarias que permitieron contextualizar los últimos diez años de finales del siglo XIX.

** Magíster en Estudios de la Cultura, mención género y cultura de la Universidad Andina Simón Bolívar (Ecuador), Historiador de la Universidad de Cartagena. Miembro del grupo de investigación Estudios de Familias, masculinidades y feminidades de la Universidad de Cartagena. Correo electrónico: cpj892005@hotmail.com. ORCID: 0000-0001-8309-9509 


\section{Introducción}

En este artículo se reconstruye la historia de las mujeres populares urbanas en la ciudad de Cartagena desde 1890 hasta 1954, periodo en que la sociedad cartagenera experimentó transformaciones que la llevaron a configurarse como una sociedad moderna. El cambio en el espacio, de un pequeño pueblo tradicional a la construcción de una nueva infraestructura inspirada en modelos europeos, constituyó el aspecto externo de un proceso complejo en el que se reconfiguraron los roles de género impuestos dentro de las familias, la identidad, los contenidos y los significados de los sectores populares y de la sociedad en general. Así, el artículo se centra en la comprensión histórica y social de las mujeres como una forma de acercarse a lo femenino en la historia popular, partiendo de los estudios locales.

Dentro de los procesos de transformación espacial y social, se destaca la participación de las mujeres populares. La primera parte de esta investigación reseña la vida de estas mujeres en el lugar que habitaron; los barrios pobres, asentamientos informales y hacinados. El paso de las mujeres a estos barrios conocidos como "extramuros" -porque se ubicaron fuera del antiguo casco amurallado- fue un elemento importante en la historia de los sectores populares de la ciudad. En la segunda parte de este trabajo, se reconstruyen algunas prácticas asociativas y procesos de organización de las mujeres populares como formas visibles y vinculantes en los variados aspectos de su vida cotidiana.

En Cartagena este tipo de análisis se debe particularmente a los cuestionamientos que surgen desde la década de 1980 en el centro del país. Según interpretaciones como la de Susy Bermúdez, la ausencia de las mujeres en los contextos históricos y sociales del país se debe al hecho de haber sido los varones blancos y alfabetizados los encargados de escribir la historia, lo cual hizo prevalecer las perspectivas androcéntricas y elitistas de esos análisis (Bermúdez, 2011). No obstante, estas menciones nacen como objeto de estudio de los movimientos de mujeres -en Latinoamérica- a partir del interés de académicas feministas de 1970. Su objetivo es demostrar que las mujeres eran participantes y no solo observadoras de los acontecimientos sociales, económicos, políticos y culturales. De esta manera, se comenzó a desvelar en la región una parte de la historia que no había sido leída antes. Debido a estos movimientos, se propuso que las diferencias entre hombres y mujeres y las identidades de género que "hasta entonces se trataban como algo natural fueran un tema digno de ser estudiado" (Puyana, 2007, p. 115).

En función de lo anterior, las mujeres objeto de este estudio no pertenecen a grupos dominantes y su participación en la política tradicional (partidos políticos, cargos en el Estado) es restrictiva. Aquellas mujeres que logran incorporarse lo hacen motivadas por las dificultades que viven en su entorno, desbordado por problemáticas como la miseria, la inseguridad, el desaseo y la falta de servicios públicos básicos como el agua. Por su condición de pobreza, las mujeres populares podían trabajar en el servicio doméstico y fuera de él. Es decir, como costureras, sirvientas y líderes en juntas locales como tesoreras y organizadoras de eventos como fiestas populares o reinados. Estos oficios les permiten visibilizarse públicamente, superar su precaria y difícil situación, y abrirse al sector educativo para la profesionalización. Estas circunstancias quedan registradas en los escritos de la época que cuestionaron la educación que las mujeres recibían en los colegios - sobre todo de la élite-, y la incertidumbre y olvido que experimentaban después de salir de ellos (Piñeres, 2008).

Para abordar el análisis, la problemática se inscribe en reflexiones teóricas y metodológicas que se han elaborado desde las categorías de sectores populares y procesos organizativos. En ese sentido, la primera permite el reconocimiento de nuevos sectores sociales como pobladores urbanos, campesinos, grupos étnicos, migrantes y mujeres. Con el reconocimiento de otros sectores sociales viene también la emergencia de nuevas realidades sociales. Allí los estudios de la historia social tratan de penetrar en los elementos de la cotidianidad en los que se encarnan los patrones culturales de cualquier grupo social; sus dispositivos de resistencia y reelaboración de la cultura dominante y el papel de ésta en la posibilidad de configurarse como un proyecto alternativo de sociedad. 
En este orden de ideas, los sectores populares involucran criterios espaciales, laborales, sociales, económicos y culturales. Hecho que cuestiona las visiones que los reducen a objetos de dominación, como grupos que son presos de un ciclo permanente de subalternidad. Estos grupos pueden demostrar grados de agencia y de creación innegables (Grignon y Passeron, 1991). Así, para el caso de las mujeres, los lugares que habitan se configuran como un espacio de participación y combinación de actividades; para ocupar el espacio público y ejercer derechos como una parte de su agencia política.

Los procesos organizativos remiten a los espacios donde se presentan las formas de interacción y asociación social. Estas acciones que han sido invisibilizadas desde una concepción tradicional del poder y de la participación política, comprenden ámbitos apropiados para la consecución de recursos, la gestión de alianzas, solidaridades y relaciones, ya sea porque comparten intereses o porque fundan espacios que permiten debatir o cuestionar nuevas ideas, crear y seguir reglas o simplemente hacerse visibles públicamente. Los procesos organizativos se encaminan a las teorías de las organizaciones que han intentado comprender las organizaciones sociales como un fenómeno social y como un concepto. Estas teorías aluden a fenómenos y procesos diversos que van desde los sistemas amplios de funcionamiento social hasta las organizaciones sociales como unidades sociales que se configuran en las sociedades. De allí, que exista un pluralismo en la definición de qué es una organización.

Así, para esta investigación se acoge la definición de proceso organizativo que coincide en señalar que son colectividades, lo que indica un grado de asociatividad donde además existen fines, objetivos y una misión común (Luhmann, 2005). Estos procesos tienen una dinámica de ejercicio de cálculo racional, se adaptan al entorno y se constituyen en un cuerpo normativo que divide funciones y tiene una autoridad. Esta reflexión surge de la relación entre organización y decisión, interpretada sociológicamente y no solo desde el punto de vista de la ganancia de racionalidad, "por lo que intenta al mismo tiempo incluir perspectivas teóricas societales en una interpretación teórica organizacional viable" (Cuesta, 2016, p. 24).
El análisis abarca métodos propios de la investigación documental y descriptiva, dados por una práctica metodológica de carácter cualitativa que permiten la construcción de una perspectiva histórica y hermenéutica. Desde estos presupuestos, las fuentes revisadas y que construyen el corpus del trabajo corresponden a recursos historiográficos que contextualizan los años de 1890 en la ciudad y publicaciones de interés histórico en uno de los periódicos urbanos que ha tenido mayor circulación en Cartagena en distintos municipios: Bolívar, Córdoba y Sucre. Se trata de El Universal, fundado por Domingo López y Eduardo Ferrer en el año de 1948, ubicado hoy en el archivo de sus propias instalaciones y la prensa comercial localizada en el archivo histórico de esta ciudad.

Para abordar este conjunto de publicaciones de acuerdo con Sandra Harding se ha evitado la posición "objetivista" que hace invisibles las creencias y las prácticas culturales del investigador, mientras que distorsiona simultáneamente las creencias y prácticas de los objetos de investigación (Harding, 1987). Tomando esto en cuenta, como investigador se reconoce la influencia que ha tenido la prensa en la integración del público, la creación de imaginarios y la trasmisión de las ideas que vinculan a unos sujetos en un contexto. Así, las imágenes y los discursos que describen los periódicos, al evocar representaciones, nos conectan con los hombres y las mujeres que permiten conocer la postura de unos y otros, pues una cosa es la realidad histórica y otra es la realidad informativa. La historiadora Gloria Bonilla afirma que "una cosa es lo sucedido y otra cosa es lo que el periódico dice acerca de lo sucedido, de modo que lo que el periódico dice se convierte en el núcleo básico de lo que es, a su vez el historiador dice acerca de lo que sucedió" (Boni1la, 2011, p. 55).

En la prensa se rastrea una postura masculina que corresponde a hombres letrados con cercanía a dueños de las imprentas de la ciudad de Cartagena, así como a escritores vinculados por lazos familiares que casi siempre ocupaban cargos gubernamentales como el de alcalde, inspector o jefe de Policía. También encontramos la voz y palabra escrita de las mujeres pertenecientes a la élite con una tradición intelectual y educación privilegiada. 
Y las mujeres de los sectores populares, cuya apropiación se hace por medio de quejas o denuncias públicas. En este sentido, podemos afirmar que estas mujeres lograron penetrar en sitios creados y reservados en principio para la intervención masculina. Desde los periódicos "las mujeres lanzan críticas respecto a la situación social que viven y de una sociedad patriarcal que las disminuía y que no creía en ellas" (Mery, 1918, p. 3).

\section{La ciudad sitiada por los pobres, la ciudad de la gente común}

Uno de los aspectos que caracterizó la modernización de Cartagena en la primera mitad del siglo $\mathrm{XX}$ fue el proceso de urbanización, en especial, en la zona centro y norte de la ciudad. En 1951 Cartagena se transformó materialmente como consecuencia del acelerado incremento de la población urbana de 9.681 habitantes en 1905 a 128.877 -un 3,2\%-. En esta transformación incidieron aspectos como un leve incremento de la esperanza de vida y la reducción de la mortalidad, principalmente infantil; una nueva tasa de fecundidad de las mujeres (cantidad media de nacimientos por mujer en etapa de fertilidad) por las mejoras en salud y la alimentación que aumentaron la tasa de natalidad (hasta su acceso a los anticonceptivos y servicios de salud sexual y reproductiva); el desarrollo de nuevos edificios en reemplazo de los conventos; y la infraestructura militar, extensiones de red vial y la conformación de nuevos barrios o modelos de organización (Aguilera y Meisel, 2009, p. 117).

En este contexto, los problemas como la miseria y la inseguridad se hicieron evidentes; la falta de vivienda, el desaseo y la insuficiencia de los servicios públicos más elementales como la electricidad y el agua potable se convirtieron en un problema social y político. Para 1920 se calculó un promedio de 2.193 viviendas en barrios y vecindades dentro y fuera del casco en la ciudad, quedando en evidencia que las élites habían construido edificios de forma planificada en el pie de la Popa, Manga, Bocagran$\mathrm{de}^{1}$, El Espinal o El Cabrero, y en los sectores populares asentamientos informales y hacinados. Estos últimos eran barrios "de pescadores en condiciones tuguriales y conjuntos de caseríos que tomaron impulso en los albores del siglo conocidos como Boquetillo², Boquerón, Pekín y Pueblo Nuevo" (Cabrales, 2000, p. 182). Estos caseríos albergaron a artesanos, obreros, inmigrantes, a las mujeres y a toda la población con menos recursos como respuesta a la ausencia de viviendas adecuadas y a bajo costo para este sector.

De acuerdo con Pedro Peña, político, escritor, agente comercial y empresario del Valle del Cauca, que viajó a esta ciudad en 1912: "fuera de las murallas, entre los palmerales de la playa, bordada con las espumas de un mar azul que se agita armonioso, se alza una modesta mansión", refiriéndose al barrio El Cabrero y "las miserables cabañas de Pekín, el barrio de los negros pescadores, en donde los cerdos y los ventrudos negritos chapotean en el mismo lodazal" (Deavila y Guerrero, 2011, p. 319). Al respecto, dice Alberto Lemaitre en Estampa de la Cartagena de ayer:

Los cartageneros que pescaban a lo largo de la muralla de Santo Domingo y la caleta decidieron un mal día mudarse allí para estar más cerca del mar, en la misma playa. Primero fue Boquetillo donde había dos casas de prostitución, un gimnasio y una cantina, luego vino Pekín barrio este de mucho empuje, ya que el 6 de enero festejaban el día de los Santos Reyes con calles vestidas, ron y música. Como ya Pekín estaba súper poblado, ni lerdos ni perezosos los que llegaron sin ranchos, dispusieron construir otro caserío que se llamó Pueblo Nuevo. Eran unos sitios de mal aspecto habitados por el populacho, los cuales construyeron sus casas con lata, cartón y paja, es decir eran adefesio que empañaba el gran sector Colonial. (Lemaitre, 1994, como se citó en Bohórquez y Hernández, 2008, p. 25)

Desde fines de la década de 1920 hombres y mujeres construyeron en estos barrios lugares para

1 Bocagrande fue la península en la que desembarcó el fundador de Cartagena, Don Pedro de Heredia con su hueste, en 1533. Hasta la década de 1920 era un inmenso playón con dunas de arenas, manglares y uno que otro pantano de aguas salobres. Con la llegada de la Andian National Corporation (ANDIAN), compañía transportadora de petróleo, se construyó un oleoducto, casas para sus empleados, así como un club.

2 Boquetillo es uno de los primeros asentamientos que comienza a edificarse a finales del siglo XIX y toma este nombre por estar cerca de la Puerta del Boquetillo al final de la playa del Tejadillo. 
vivir, le dieron identidad, nuevos contenidos y significados a la ciudad y a los sitios que habitaron (Redondo, 2004). Para esta misma época se inició la reubicación y los desplazamientos de las zonas a otros espacios como son los predios de Canapote al norte de la ciudad, ya que con sus problemas e imagen afeaban los alrededores del casco colonial. De acuerdo con el historiador Maico Pitalua (2014), esta etapa histórica justifica "el diseño de lo que se podría denominar un primer plan de ordenamiento territorial" (pp. 22-23). Este diseño respondió a la construcción de vías principales, instalación de mansiones inspiradas en modelos europeos y la consolidación de zonas para actividades económicas como el turismo, puesto que esta forma de ocupación fue entonces "por las vías de hecho como la toma de tierras en lugares aledaños a la urbe, lo que hoy se conoce como la urbanización pirata" (García, 2013, p. 122).

En este sentido, los años desde 1920 hasta 1954 son vitales para comprender la configuración de la ciudad y para entender las circunstancias que motivaron a hombres y a un gran número de mujeres a migrar a Cartagena, conformar los sectores populares, construir espacios y volverse protagonistas de su propia ciudad y ciudadanía en los barrios de los pobres. Barrios donde se establece un tipo de relación ecológica, económica y social con un sector delimitado geográfica y simbólicamente. En la ciudad, aunque los componentes son similares a la anterior, el tipo de relación es más abstracta, de mayor alcance y más fluida (Velásquez, 1997).

\section{La ciudad en las voces de las mujeres: sus actividades}

Cartagena, como una de las principales capitales colombianas después de 1948, recibió migrantes por el despojo de tierras y bienes en los campos, la apropiación de cosechas, el incendio de casas y trapiches, la destrucción de cementeras y los desplazamientos masivos de campesinos hacia otras zonas de su misma filiación partidista, es decir, liberales o conservadores (Meertens, 2000). De esta manera, se inició la invasión, conformación y poblamiento de desplazados de los departamentos de Córdoba, Sucre y Antioquia hacia terrenos baldíos como San Francisco, Nuevo Porvenir, República de Venezuela, Chile y Los Cerros -sur oriente de la ciudad-para no pagar arriendo o conseguirlos a un menor precio y reconstruir nuevos lugares de habitación. Respecto a la situación, periódicos como $E l$ Fígaro informaron:

Ayer llegaron a la ciudad [Cartagena] procedentes de los corregimientos costaneros de Puerto Escondido y Cristo Rey, que pertenecen respectivamente a los municipios de San Bernardo y Cereté [Córdoba], grupos de ocho a diez vecinos conservadores de aquellos corregimientos que se [sic] han venido huyendo de la persecución que contra ellos ha [sic] iniciado los inspectores de policía, Campo Elías Galván, del primero, y Cayetano Marsiglia, del segundo, con la tolerancia de los alcaldes. El delito de los vecinos mencionados consiste en haber sido partidarios de la candidatura del doctor Ospina Pérez y haber trabajado con decisión para su elección.

Los fugitivos visitaron la dirección departamental del partido a cuyos miembros refirieron lo que les ocurría y solicitaron amparo para poder regresar a sus pueblos sin temor, donde han dejado sus familias expuestas a todas las contingencias. (Persecución a los conservadores, 1948, p. 4)

A la mayoría de hombres y mujeres pobladores de zonas rurales se sumaron aquellos que fueron producto de la migración intraurbana, entendida como la movilidad espacial que ocurre entre los límites de una zona urbana, en ocasiones, en barrios ya constituidos. En Cartagena, este mecanismo de supervivencia de las poblaciones, principalmente de menores recursos de la zona suroriental y suroccidental de la ciudad, ayudó a entender cómo los nuevos barrios se convirtieron en núcleos de atracción al brindarle nuevos asentamientos y la oportunidad de hacerse una vivienda a bajo costo. Estos nuevos barrios surgieron como una alternativa al no poder pagar el alquiler en barrios residenciales con ostentosa arquitectura republicana francesa (Cabrales, 2000).

Si bien los flujos migratorios dinamizaron el crecimiento urbano, también causaron un aumento en los problemas sociales, ya que la forma en que se planeaba la organización de la ciudad no previó recursos para el desarrollo de una adecuada infraestructura y establecimiento de servicios públicos de los nuevos barrios. 
Al indagar por las mujeres populares, se encontró que ellas migraron a Cartagena con la esperanza de paz y progreso familiar, como es el caso de Josefa, oriunda del departamento de Sucre, que se convertió en líder comunitaria de la ciudad. Josefa recuerda haber llegado al barrio Chambacú, comunidad creada por africanos libres, exactamente "al teatro Variedades; donde había una señora que tenía venta de comida, y la señora en la noche se dio cuenta de que había una niña, que no la veía con nadie, la mujer se preocupó y me cogió" (Josefa Morelo, comunicación personal, 15 de mayo 2007) ${ }^{3}$.

Este fragmento del relato de Josefa, aunque no muestra las necesidades por las que ella atraviesa para desplazarse y llegar a Cartagena, ni sus expectativas para habitar esta ciudad, permite conectar una experiencia de la cotidianidad con lo social y lo público. En otras palabras, cuando la situación de violencia, abandono o rechazo le sorprende en el interior de su hogar, ella debe salir para encararlas en el escenario público.

Las mujeres que ocuparon y poblaron estos nuevos barrios de la ciudad, habían abandonado sus fincas y todo lo que tenían para que no las mataran, como Olga, quien narra en 1948 los atentados contra liberales en el municipio de San Pelayo, en Bolívar:

Anoche se registró otro hecho de sangre en el caserío Boca de López del municipio de San Pelayo, del cual fue protagonista principal un representante del actual gobierno. Como a las diez de anteanoche, se presentó al caserío nombrado el señor Claudio Quintero, solicitando por el regidor de la policía del lugar y manifestando públicamente que desempeñaba las funciones del alcalde [de] San Pelayo y necesitaba practicar una requisa en la casa del señor Francisco López Nieves, ciudadano liberal residente en el caserío tantas veces nombrado. (Nuevos atentados contra liberales en San Pelayo, 1948, p. 6)

En el relato de Olga se hacen evidentes las disputas entre integrantes del gobierno nacional pertenecientes a los partidos políticos liberal y conservador. Disputas que justificaron la aparición de actores armados bajo el nombre de "Pájaros" (civiles armados laureanistas) y "Chulavitas" (policía o matones conservadores). Asimismo, Olga ayuda a entender las razones por las que Cartagena, siendo la ciudad más cercana que tenía el municipio de San Pelayo, se volvió polo de atracción de mujeres y hombres campesinos al representar representar opciones de estudio y trabajo.

Es así como los barrios más pobres de la ciudad y los sujetos que habitaron en ellos asumieron criterios espaciales, laborales, sociales, económicos y culturales. En el caso de las mujeres, su experiencia se concretó en expresiones o formas de sociabilidad, acciones que a su vez propiciaron la conformación de identidades grupales y con frecuencia contribuyeron a atender reclamos sociales. A continuación se analizan algunos roles que fueron esenciales en la formación de la identidad de estas mujeres.

\section{a. Costureras, comerciantes, sirvientes domésticas $y$ prostitutas}

Cuando la ciudad comenzó a dar visos de recuperación y progreso económico, las mujeres se desempeñaron como secretarias, archiveras, modistas, costureras, tejedoras, jaboneras y hasta prostitutas. La incorporación a estas actividades de la vida ciudadana se dio en medio de las "casas de citas", fábricas y empresas de extranjeros, incluso de empresarios ya radicalizados como Juan B. Mainero y Trucco, los Aycardi, al igual que los Vélez Danies (Solano, 1994) que albergaron la industria textil, de cigarrillos y jabones dentro del antiguo recinto amurallado. En este sentido, los desplazamientos que realizaron las mujeres fueron más reducidos, a diferencia de los hombres que debían trasladarse a las periferias de la ciudad donde estaban los talleres de mecánica para las operaciones del ferrocarril Cartagena-Calamar o las imprentas (Bonilla, 2011, pp. 186-192). Varios de los oficios ya mencionados fueron destacados por una publicación de la revista de cultura femenina y divulgación turística Lumbre:

3 La entrevista fue concedida a María Josefina Gonzales en el marco de su trabajo de grado (maestría) titulado Mujeres populares en la construcción de autonomía y ciudadania: entre el transcurrir de sus vidas y la fundación de sus barrios. Bogotá: Universidad Nacional, Escuela de Estudios de Género. 
Ellas, las mujeres que trabajan, han aristocratizado y embellecido el ambiente de las oficinas; su fresca gracia ha llevado a fábricas, talleres y empresas comerciales una nota de distinción y cultura; ha creado un nuevo clima de respeto y de mesura para los jefes y compañeros; delante de ellas, los varones tienen que forzosamente olvidar sus charlas equivocas, sus chistes de mal gusto, sus palabras ásperas; ellas son las que han puesto sobre los escritorios la viva pincelada fragante del gajo de rosas, las que han colgado en el muro severo dulce imagen del Corazón de Jesús, las que han encendido al pie de la efigie del Crucificado la lamparilla perenne que cifra toda tradición de fe cristiana. (Las mujeres que trabajan, 1949, p. 13)

Este texto sugiere que las mujeres realizaban labores fuera del recinto amable del hogar, a menudo, respondiendo a las exigencias de la modernidad y progreso de la ciudad, pues eran merecedoras de respeto al igual que los varones. Sin embargo, este reclamo no deja ver que la demanda laboral en los nuevos espacios era absorbida por un número elevado de trabajadoras en el servicio doméstico como lavanderas, sirvientas o vendedoras de productos en el mercado; oficios que garantizaban mejores condiciones para sus familias y daban pie a luchas organizadas para servir a los vecinos en los barrios populares de la ciudad. Por el contrario, los adjetivos tales como aristocratizados y embellecido, gracia, distinción y belleza permiten entender que son atribuidos a otro tipo de mujeres, perteneciente a los sectores medios o altos de la época.

Ahora bien, de acuerdo con Beatriz Gallego (2011): "tradicionalmente la división de roles en función del género ha jugado un papel fundamental en la vida de hombres y mujeres que, por el hecho de serlo, debían desempeñar determinadas tareas tanto en la familia como en la comunidad". En otras palabras, las mujeres en sus casas o "en lo que hace las veces de casa" deben cumplir como esposas, madres e hijas alimentando, educando, cuidando y atendiendo a la familia, y los hombres orientan sus actividades en la calle, donde trabajan, se divierten o se embriagan.

Esta identificación de las mujeres con la maternidad y el hogar ha sido una constante en la historia y ha fortalecido discursos como el de las bondades de la domesticidad y la separación de los sexos en dos esferas de actividad diferenciadas. De esta manera, "al varón se le asigna un papel social en la esfera pública de la producción y de la política, a la mujer se le remite al recinto cerrado del hogar" (Bonilla, 2011, p. 61). Sin embargo, la aparición de espacios distintos a la vivienda doméstica, para el ocio y esparcimiento de la élite, como clubes, teatros, salones de arte y el crecimiento de nuevas fábricas desde finales del siglo XIX, le permite a las mujeres cumplir con funciones fuera de sus roles en la vida privada, nuevas formas de relación y convivencia con otros hombres y mujeres. Estos roles, que tienen restricciones de clase, permiten cierta movilidad en los espacios que las mujeres tienen para su sociabilidad.

\section{b. Madres y líderes}

La separación socio-espacial entre el mundo privado y sombrío de las mujeres y el mundo público, visible y abierto para los hombres apareció, según el enfoque de género, con el capitalismo, cuando el mercado rigió en el mundo exterior. Se trata de un nuevo modelo que dominó para la familia burguesa en el siglo XIX, pero que en el XX se convirtió en el modelo principal de la clase obrera: "la necesidad de acumulación de plusvalía hace que se explote por igual al hombre, la mujer y al niño de la clase obrera" (Astelarra, 2003, p. 26). Esto quiere decir que con el sistema capitalista se replantearon el sistema de vida y las relaciones de los hombres y mujeres con su entorno, ya que "son objetos de uso y participan de relaciones de compra y venta a través del dinero; pierden por tanto, su antiguo valor afectivo y emocional" (Garcés, 2004, p. 130).

En Cartagena este panorama se reflejó en la construcción de parques, clubes y teatros que constituyeron un privilegio para las mujeres pertenecientes a élites. Fábricas y talleres para las mujeres de sectores medios y oficios en el servicio doméstico para las mujeres populares (lavanderas, sirvientas o vendedoras de productos en el mercado para las primeras) que podían reforzar los papeles y valores tradicionales del género. Para el caso de la ciudad, es interesante ubicar escenarios de recreación que surgieron para los sectores populares a finales del siglo XIX, de la mano del arzobispo Pedro Adán Brioschi, en una pastoral quien diferenciaba a los artesanos, 
a los que llama "hombres de abajo", de los “...hijos del pueblo... últimos grados de la sociedad [entre los que ve] el desenfreno de las pasiones y la lobreguez de los vicios" (Brioschi, 1898, p. 84-86, como se citó en Solano y Flórez, 2011, p. 49).

Para estas últimas, también sirve de ilustración la aparición del Gremio Obrero Femenino de Cartagena que tuvo lugar en el seno de una de las sesiones de la "Liga Obrera" de esta ciudad, donde un número regular de mujeres obreras se reunieron con el fin organizar un gremio. Si bien existían gremios de panaderos, choferes o carpinteros por colocar algunos ejemplos, este movimiento llamó la atención en tanto se vio involucrado en una serie de actividades que resultaron beneficiosas para la comunidad (Cera, Polanco y Castrillón, 2011). Indistintamente, tanto las mujeres pertenecientes a élite, a sectores medios y populares, accedieron a las tareas productivas, a los bienes y a los servicios de la ciudad. Las últimas, en particular, alcanzaron nuevas formas de sociabilidad y experiencias de organización para la consecución de recursos y solución de los problemas más apremiantes en sus territorios. Dicho de esta manera, era posible encontrar a las mujeres en la calle y en espacios diferentes de la vida doméstica. No obstante, más allá del estatus social que pudo generar la vinculación a obras que eran competencia del Estado, como sucedía con las élites, las mujeres populares aprovecharon esta coyuntura para sacar a la luz sus problemas cotidianos y convertirse en interlocutoras con la administración local y nacional. En otras palabras, el oficio de madre se fue transformando en el de líder.

Por ejemplo, publicaciones de inicios del siglo $\mathrm{XX}$ en Cartagena registraron el trabajo de grupos de mujeres por medio de obras de caridad y beneficencia cuya descripción y relatos son aislados, es decir, predominaba la información de la élite sobre lo popular. Beatriz Castro (2007) define a la caridad como un deber religioso, un compromiso moral en busca del progreso social, una solución para las amenazas de los problemas sociales y las desarmonías, y un medio para ganar estatus social. En este sentido, los intereses de estos actores respondían a la situación que provenía del periodo colonial y que permanecían en los territorios americanos, encabezados por la Iglesia católica. También, respondía a la situación de pobreza en que vivía la mayor parte de la población, sobrellevada a través de los hospitales, hospicios o asilos, y las mujeres de la élite quienes aprovechaban como un instrumento de "perfeccionamiento espiritual", ya que podían alternar sus funciones en la casa y la iglesia.

No obstante, por medio de cartas, memoriales $\mathrm{y}$ denuncias públicas en los periódicos urbanos y revistas, las mujeres populares expresaron con sus palabras y desde sus lenguajes la experiencia de vivir en medio de dificultades y problemas como las condiciones precarias de la vivienda, la inseguridad, el desaseo o la insuficiencia de servicios públicos básicos. Al respecto, en un memorial de El Universal presentado el 15 de julio de 1954 se menciona:

\section{Somos contribuyentes y tenemos derecho a que se nos atienda a nuestras necesidades [vecinas del barrio Torices]. No deseamos vivir más en un Ba- rrio abandonado por las autoridades municipales, donde se ha permitido que se instale el basurero de la Ciudad, verdadero criadero de moscas y mos- quitos que están diezmando con gastroenteritis y tifo la población.}

Tenemos derecho a pedir, y obtener de los encargados de velar por la salud y bienestar público, se nos proteja de los elementos que hoy tratan lanzarnos fuera de nuestros hogares. Creemos tener los mismos derechos y garantías que se les dan a los habitantes de los Barrios privilegiados de Popa, Manga y Bocagrande. (Quejas de unos vecinos del barrio Rodríguez Torices, 1954, p. 6)

En esta cita aparece con toda claridad que las mujeres, vecinas del barrio Torices, asumían tener los mismos derechos que los habitantes de los barrios más acomodados que se ubicaban en las cercanías del centro de la ciudad. Concebían que su acceso podía representar un "cambio hacia una mayor integración social e igualdad que significa una "ciudad prospera".

Este tipo de noticias descritas por la prensa son significativas en la medida en que dialogan con otra dimensión de sus vidas: las personas con que se relacionan y el ámbito público donde se desarrolla su cotidianidad con otros hombres y mujeres que no son de sus mismos barrios. Además, comparten necesidades comunes, elaboran intereses colectivos y despliegan acciones conjuntas, organizadas o no, 
"a través de lo cual forman un tejido social y un universo simbólico que les permite irse reconociendo como vecinos y relacionarse con otros miembros de la ciudad" (Torres, 1999, p. 8).

En otra solicitud publicada por El Universal, firmada por hombres y mujeres residentes del barrio Daniel Lemaitre, se enumera lo siguiente:

$1^{\circ}$ Arreglo de la Avenida Olaya Herrera y calles adyacentes. Esta Avenida, que es la única vía de acceso al barrio, fue arreglada por nosotros en el mes de octubre de 1953, faltando petrolización, cosa que no hicimos por falta de recursos, pero que hoy, con la ayuda del Municipio podemos hacer, aportando cada vecino una cuota proporcional a sus posibilidades económicas. Pues, esta vía la han destruido los camiones del Aseo Municipal que cruzan continuamente por allí.

$2^{\circ}$ Instalación de la luz eléctrica en la Avenida Olaya Herrera y algunas otras calles. Estas calles necesitan con urgencia el alumbrado eléctrico, porque están rodeadas de monte en donde crían cantidades de culebras venenosas, inminente peligro para todo el que por esas calles transite de noche. Ojalá que la autoridad competente tome medidas para que los propietarios de los solares se vean obligados a desmontar.

$3^{\circ}$ Arreglo del terreno destinado para el parque del barrio. Según nos hemos informado, el Municipio ha destinado un lote de terreno en este lugar para la construcción de un parque, lo cual nos interesa sobremanera y agradeceríamos al señor Alcalde nos indicara el lugar y diera autorización para encargarnos del arreglo, para que los niños tengan un lugar exclusivo para jugar.

$4^{\circ}$ Buses urbanos para este barrio, servicio urgentísimo. Ojalá el señor alcalde se digne interesarse en este sentido, ya que las veces que hemos solicitado a la dirección del Tránsito nos ha sido imposible obtenerlos; pues éste es uno de los servicios más urgentes del Barrio, ya que en él residen más de ciento veinte (120) familias que se trasladan continuamente de uno a otro lado de la ciudad, teniendo que caminar aproximadamente un kilómetro para tomar el Bus de Torices que cruza para el Barrio de Crespo. Desviando para nuestro barrio dos o tres de estos buses, se resolvería nuestro penoso problema. (Servicios para el barrio Daniel Lemaitre reclaman los vecinos, 1954 p. 8).

En estas denuncias se puede evidenciar que de las necesidades enumeradas sobresalen dos: la instalación de la luz eléctrica y el servicio de los buses. Al pie de la petición se encuentran los nombres de Pedro de J. Bonilla, Ignacio Salazar, Isidro Morales Ochoa, Manuel Antonio Vargas, Emilia Romero, Bienvenida Corrales y otros vecinos que describen la precariedad y limitaciones de su barrio. Este memorial, al encontrarse firmado por un grupo significativo de mujeres, nos permite comprender el uso y apropiación de los medios de comunicación (periódicos y revistas), con propuestas para cuidar sus territorios y buscar el progreso de los mismos. Aunque en la exposición de los nombres la prensa no sugiere si eran o no dirigentes, lo importante es que están logrando un protagonismo por medio de una tarea que culturalmente se les ha asignado y, desde allí, movilizan estrategias que atienden a sus necesidades.

El caso del alumbrado eléctrico llama la atención porque se trata de un fenómeno que afectó a la mayoría de las ciudades colombianas. Dada la escasez de los fondos municipales, este servicio público no solo tardó en llegar a Torices, sino a numerosos barrios que hoy conforman la zona sur y sur oriental de la ciudad. Así, es importante examinar por qué las mujeres reclaman un recurso y un derecho a la vez. Para muchas mujeres, la protección de los miembros del barrio significa su propio cuidado.

Una aproximación a la condición de vulnerabilidad de las mujeres se encuentra quizás en el número de delitos para la época. De acuerdo con Castrillón y López (2016), hasta la década de 1950 se pudieron rastrear 134 delitos protagonizados por mujeres, de los cuales $80 \%$ de ellos corresponden a escándalos y riñas y el 8,2\% a lesiones y agresiones físicas. El resto de los hechos delictivos protagonizados por mujeres $(11,8 \%)$ corresponde a homicidios, infanticidios, robos, hurtos y dos casos de brujería (p. 32).

La energía eléctrica data de finales del siglo XIX gracias a las ideas de empresas privadas de trasladar plantas de otros países y de concesiones que obtenían para prestar el servicio en las ciudades. Sin embargo, para Cartagena como sucedió en Bogotá (1889), Bucaramanga (1891), Cali (1910) o Medellín (1895), la luz fue un privilegio para el comercio y los sectores más acomodados hasta 1940. Posteriormente, los intentos - muchas veces lentos-de las 
autoridades locales por generar servicios públicos domiciliarios se desplazaron hacia los sectores populares que alumbraban sus viviendas con faroles de velas cebo y cocinaban con leña. Finalmente, el servicio se nacionalizó en $1962^{4}$.

Respecto a las otras necesidades que describe el memorial como la cuota para mejorar la vía de Olaya Herrera y el arreglo de un terreno para la construcción de un parque para la diversión de los niños, aunque no detalla si es idea de los hombres o las mujeres, se puede suponer que era iniciativa de las últimas, es decir, Emilia Romero y Bienvenida Corrales, ya que dentro de los roles asignados por la sociedad estaba la madre y debían estar vinculadas a actividades de solidaridad. No obstante, encontramos que dentro de estos arreglos hay una oportunidad que aprovechan como espacios para la socialización con hombres, que son la mayoría, y otras mujeres vecinas del barrio.

Por las noticias descritas en la prensa cartagenera, el problema de la inseguridad en los barrios más pobres de la ciudad fue todo menos una novedad para sus habitantes que los poblaron hacia la zona sur y suroriental. ¿De dónde surgió dicha actividad? Los reportes de la inseguridad por parte de las mujeres en la década de 1940 muestran que ellas tuvieron un importante papel en la visibilización de los numerosos conflictos que se producían cerca de sus casas. Estas situaciones muestran que sus vidas no transcurrían exclusivamente en los hogares y se convirtieron en prácticas que incidieron en la creación de un sentido de pertenencia hacia sus barrios, a un "grupo social integrado a un espacio común" (Ramos, 1995 como se citó en Torres, 1999, p. 19). Sin embargo, debemos tener en cuenta que en las denuncias anteriores se menciona la falta del alumbrado eléctrico como una causa de la inseguridad; también inciden factores como: "la economía informal, los altos niveles de desempleo, el crecimiento desordenado y vertiginoso, el aumento de sectores de población más pobres y la vivienda precaria" (Bonilla, 2011, p. 275).

Ahora bien, cuando las mujeres y sus familias arribaron a los nuevos barrios de la ciudad, una preocupación particular fue la de tener un techo para sus hijos. Muchos de los predios que se encontraban deshabitados no tenían vivienda. Por ello, a través de la prensa, ellas mostraron su inconformidad y solicitaron ser reubicadas por las autoridades municipales como había sucedido con los antiguos asentamientos de Pekín, Pueblo Nuevo y Boquetillo en 1920.

En el despacho de la Alcaldía de Cartagena, por ejemplo, se presentó el 23 de julio de 1954 un grupo conformado por ocho mujeres que vivían en los terrenos de Zaragocilla con el objeto de hablar con el jefe de despacho sobre la situación que les había creado al ser notificadas por el director para que desocuparan las casas por estar ubicadas en terrenos de su propiedad. Estas mujeres buscaban al capitán Cervantes para que él, como alcalde, tomara las medidas que considerará conveniente a manera de indemnización. Este grupo alegaba que:

Desde hace varios meses se nos viene hablando de la necesidad de hacer desalojar a los moradores de Zaragocilla por considerar peligrosa la ubicación de nuestras casas para la salud de sus ocupantes y ahora, el director del hospital no los ha hecho saber en una nota dirigida a cada uno, y en la que se da un término para que abandonemos los predios. Como quiera que se trata de un problema social pues con la medicina resultan afectadas más de 50 personas, la alcaldía debe estudiar y resolver la situación conforme a los intereses de los asociados ya que la casa es el único patrimonio con que contamos. Somos familias pobres que carecemos de medios para comprar tierras en otros lugares y levantar sus viviendas. (Se crea un problema social en los terrenos de Zaragocilla, 1954, p. 5)

Al reseñar la vida de las mujeres populares en el lugar que habitaron se encuentra un contexto de precariedad y limitados recursos de subsistencia que les provee formas para visibilizarse y organizarse. Acciones que se producen inicialmente por los desplazamientos y que les permiten participar de los diferentes lugares y espacios de unión en la ciudad por los que acceden a los servicios para inserción laboral y a las actividades urbanas. Cuando la ausencia

4 Con la Ley 109 de 1936 y el Decreto 1607 de 1937 se sancionan responsabilidades por parte del Estado en el desarrollo del sector eléctrico y en general de los servicios públicos. 
de viviendas adecuadas, de servicios públicos y otros problemas privados aparecen en este contexto, se convierten en detonantes para que las mujeres reclamen e interpelen acciones por parte del Estado y el gobierno local. Entre tanto, las mujeres asumen y apropian trabajos de cuidados organizados porque históricamente se les ha asignado ese rol como madres, esposas o hijas, que fue "transformado en un atributo natural en vez de ser reconocido como trabajo ya que estaba destinado a no ser remunerado" (Federici, 2013, p. 37). Sin embargo, cuando ese cuidado sale del hogar expande las fronteras de los barrios, revoluciona sus vidas e incide en las políticas públicas.

\section{Nuevas formas de relación: las mujeres populares fuera de sus viviendas}

Al salir de sus casas, las mujeres populares no solo estaban buscando autonomía y visibilización mediante actividades que eran propias del ambiente familiar, sino que se interesaban por interactuar con sus semejantes, así como el uso de los bienes y servicios que les ofrecía la ciudad para experimentar un cambio en sus vidas.

A medida que las relaciones interpersonales de las mujeres en los nuevos barrios crecieron y se diversificaron, por la caridad, lazos de amistad o para solucionar problemas, su participación se hizo evidente en las distintas formas de sociabilidad y organización. De acuerdo con Maurice Agulhon (1977), estas formas de asociación se muestran como un proceso de complicación social que le permite a los individuos apartarse de su principio natural, único e individual y lo vincula a una interacción social, permitiéndole definir su personalidad e independencia (Chapman, 2015).

Este principio natural para las mujeres reside en que el trabajo doméstico le fue impuesto por su relación con la casa y el ambiente familiar, direccionado por la cultura católica, quien las prepara para este rol y las convence para tener hijos y marido. Es decir, para la formación de una familia como el fin máximo de lo que hoy llamamos proyecto de vida (Federici, 2013). Por lo tanto, las mujeres asumen tareas que derivan de la actividad reproductiva y en el trabajo productivo, aunque en ninguno de los dos casos sea remunerada.
En la prensa de Cartagena se da a conocer el buen papel que desempeñan las mujeres en el escenario público, empero más allá se teje el asunto de la sociabilidad. En este sentido, uno de los casos más representativos en el contexto que ocupa nuestro trabajo y que es ilustrado por diversos textos, es el de la Sociedad de Amor a Cartagena (en adelante SAC) que destacamos por convertirse en un espacio para que las mujeres populares coincidieran con sus iguales para ayudar a los vecinos, entablar lazos de amistad y gestionar con el Estado recursos por las condiciones de precariedad en que vivían.

Exposiciones, presentaciones de teatro, fiestas y el reparto de regalos para ayudar a la población necesitada, a niños huérfanos y pobres se convirtieron en actividades que lograron articular las relaciones de mujeres de la élite con las populares. Casi siempre se trató, según Lola Luna y Norma Villarreal (1994), de los "arreglos que permitía el sistema de género" (p. 68) en ambientes domésticos, reiterando su misión como madres o esposas y en lo referido a la solidaridad social y obras caritativas. Empero, como ya hemos anotado, complementan las formas de socialización que constituyen una importante fuente para apoyar las precarias condiciones de sus familias y la de sus vecinos.

Otro elemento de la SAC que actúa como cohesionador en la vida de las mujeres populares con las de la élite fue su centro social, donde se dictaban cursos de capacitación en matemáticas, recreación, artesanía, teatro, corte y costura. En la medida en que unas mujeres apoyaban con su labor y dinero a otras menos favorecidas, se modifica la idea de la mujer en su rol familiar y en su modo de acceder a los bienes y servicios de la ciudad. Además, estas mujeres aprovechan estos espacios para el "esparcimiento, solaz comidillas y chismoseo" (Londoño y Saldarriaga, 1996, p. 50). El 27 de abril de 1954 en El Universal se realiza una pronunciación por esta labor:

El costurero de la SAC inició a principios de año las clases de Corte y Costura, para niñas y mujeres de los barrios humildes, aprovechando las máquinas conseguidas por la Presidenta de la Institución durante su viaje a los Estados Unidos, en cumplimiento de su Beca Líder Grand, ofrecida por el Departamento de Estado del Gobierno 
Americano. La institución ha adquirido seis máquinas más y actualmente se amplía a 250 el cuerpo de alumnas para la modistería. (El costurero de la SAC, 1954, p. 12)

Vemos entonces que para el periódico local es más llamativo describir la beca que le posibilitaba a la señora Ayda Porto de Gerdts, miembro de la junta directiva, asumir sus funciones como presidenta del costurero, que dar cuenta de cómo se establecen las relaciones interpersonales de las mujeres quizás estables y duraderas.

Para destacar el papel que cumplía la SAC en la confluencia de mujeres de distintos sectores de la ciudad, en la revista Lumbre se realizaron diversas publicaciones en sus diferentes números de cuando se hacían repartos de cuadernos, comestibles, vasos o primeros auxilios a las escuelas de los barrios populares:

En el mes de septiembre del presente año la Sociedad de Amor a Cartagena hizo repartos a las siguientes escuelas: No. 7 y 17 en el barrio la Esperanza dirigidas por Elsa Yanes de Taborda y Anatilde de Bonfante, No. 8 y 18 en el barrio Bruselas, dirigidas por Anila de Alba, y Sarita de Arrieta, No. 9 y 19 en el barrio San Isidro, dirigidas por Ernelda Bustos de Llamas y Yolanda Castro, y la No. 10 y 20 en el barrio Escallón Villa dirigidas por Rita Pájaro e Isabel C. de Jaramillo. (Estadísticas de los últimos repartos, 1954, p. 14)

En este sentido, los desplazamientos de las mujeres de la élite a los sectores populares se convierten en espacios de encuentro y relaciones entre el espacio doméstico y la vida pública. Aunque en la mayoría de los casos las publicaciones informan cómo las mujeres de la élite lideran, a través de sus pensamientos, las diferentes luchas en beneficio de los grupos que componen a los barrios populares, esto no se podrían comprender si ellas no salieran de sus casas y buscaran romper con una barrera que impuso al cuidado y al amor como el trabajo, la limpieza y la preparación de alimentos. Un espacio que las excluía de las decisiones que afectan a sus familiares, vecinos y a la ciudad.

También hemos visto que las prácticas de sociabilidad casi siempre se articulan a la caridad usada por las mujeres de la élite, pero no restringían la vinculación de aquellas en los barrios populares. Esta situación permite la profesionalización de oficios y la participación del mercado laboral, aunque no accedan a un salario. Asimismo, como sucede con las mujeres de las élites, las mujeres de los barrios populares ganan un estatuto social por la agencia política cuando establecen relaciones entre el Estado y la sociedad.

\section{Conclusiones}

En Cartagena, los avances del proceso de modernización no beneficiaron ni garantizaron el acceso de manera equitativa para toda la población. Los barrios que emergieron con sus pobladores sufrieron problemas de miseria, precariedad y recursos limitados para su bienestar. Sin embargo, dichos pobladores activaron relaciones sociales con los vecinos y familiares, a partir de las cuales crearon lazos de identidad y solidaridad. Además, potenciaron prácticas de asociación y organización que atendieron a sus necesidades y definieron el protagonismo de las mujeres populares.

El desarrollo de nuevas formas de relación y organización, construyó un camino para que las mujeres atendieran las necesidades más apremiantes y responsabilidades con sus hijos, su familia, pareja o la comunidad. También se convirtió en una motivación para que en el momento en que las mujeres salieran de sus casas pudieran acceder a los bienes y servicios de la ciudad. Asimismo, les permitió apropiarse con los nuevos tiempos y espacios públicos como parques, colegios, hospitales e instituciones públicas.

En este contexto, se replantearon las relaciones sociales de los hombres y mujeres con su entorno, ya que la vivienda doméstica o la calle dejó de ser exclusiva; en especial, por el crecimiento de fábricas y lugares para el ocio y esparcimiento. Las mujeres populares movilizaron un conjunto de prácticas y actividades destinadas a superar sus necesidades. Al mismo tiempo, retaron las relaciones de poder desiguales al asumir las incapacidades del Estado y los mecanismos políticos tradicionales. En esa dirección, se trató de proponer la siguiente línea de análisis: las mujeres populares a través 
de la esfera cotidiana, de sus barrios y trabajos de cuidado, atendieron los problemas sociales como la insuficiencia de servicios básicos. No obstante, se debe tener en cuenta que cuando las mujeres escogieron socializar con sus iguales o con los hombres, estaban buscando un respaldo para luchas organizadas y para participar como interlocutoras ante las instituciones del Estado. Este rol, que parece natural, buscaba ser visibilizado a través de las negociaciones con el poder y las nuevas identidades colectivas del mundo social.

Aquí es importante destacar que esta interlocución que realizaban las mujeres con el aparato estatal, determinada por la idea naturalizada de las mujeres igual a madres, igual a amas de casas, con una identidad homogénea a la cual no se le cuestiona, sentó sus bases en los programas de beneficencia encabezados por la iglesia católica. Dichos programas tenían la misión de trasmitir y reforzar un saber que transitaba en la familia cuidando, cocinando, lavando o planchando. Empero, independiente de los intereses que perseguía la institución religiosa, esta situación brindó una oportunidad para que las mujeres compartieran experiencias personales.

Ahora bien, los trabajos de cuidado no buscaban satisfacer solamente las necesidades materiales y emocionales de la población, de los niños y de los adultos; respondían también a una estrategia por parte de los mecanismos políticos tradicionales y del aparato de desarrollo para canalizar el salario de las mujeres a partir de sentimientos como el amor o el matrimonio. Sin embargo, este trabajo organizado produjo nuevas manifestaciones: las mujeres se volvieron protagonistas y ganaron un estatus, se generaron encuentros con los grupos de la élite que los convirtió en plataforma para que las mujeres populares accedieran a sus necesidades prácticas. Finalmente, se preparó el terreno para el desarrollo de políticas públicas que garantizaran el disfrute de iguales de derechos y oportunidades.

\section{Referencias bibliográficas}

Aguilera, María., y Meisel, Adolfo. (2009). Tres siglos de historia demográfica de Cartagena de Indias. Cartagena, Colombia: Banco de la República.
Agulhon, Maurice. (1977). Le cercle dans la France bourgeoise, 1810-1848. Étude d'une mutation de sociabilité. París, Francia: Libraire Armand Colin.

Astelarra, Judith. (2003). ¿Libres e iguales? Sociedad y política desde el feminismo. Santiago de Chile, Chile: CEM.

Bermúdez, Suzy. (2011). Método, historia y mujeres. En Luz Gabriela. Arango y Mara Viveros (Eds.), El género: una categoría útil para las ciencias sociales (pp. 97-139). Bogotá, Colombia: Universidad Nacional de Colombia.

Bohórquez, Nellys., y Hernández, Carmen. (2008). Barrios populares. Una forma de construir ciudad en Cartagena de Indias. Casos: Pekín, Pueblo Nuevo y Boquetillo (tesis de pregrado). Universidad de Cartagena, Cartagena, Colombia.

Bonilla, Gloria. (2011). Las mujeres en la prensa de Cartagena de Indias 1900-1930. Cartagena, Colombia: Editorial Universitaria.

Cabrales, Carmen. (2000). Los barrios populares en Cartagena de Indias. En Haroldo Calvo y Adolfo Meisel (Eds.), Cartagena de Indias en el siglo XX (pp. 181209). Bogotá, Colombia: Banco de la República.

Castrillón, Carlos., y López, Lizett. (2016). Al límite de la violencia de género: representaciones de transgresiones protagonizadas por mujeres en la prensa cartagenera, 1940-1950. La Manzana de la Discordia, 11(1), 29-39. doi: 10.25100/lamanzanadeladiscordia.v11i1.1632.

Castro, Beatriz. (2007). Caridad y beneficencia. El tratamiento de la pobreza en Colombia 1870-1930. Bogotá, Colombia: Universidad Externando de Colombia.

Cera, Raúl, Polanco, Nathaly., y Castrillón, Carlos. (2011). "Territorios prohibidos". Las mujeres en el camino hacia la vida política, Cartagena durante la primera mitad del siglo XX. Palobra, (12), 220-235.

Chapman, Willian. (2015). El concepto de sociabilidad como referente del análisis histórico. Investigación y desarrollo, 23(1), 1-33.

Cuesta, Irina. (2016). Redes de mujeres en el Occidente colombiano. Procesos organizativos y sentidos de acción (tesis de maestría). Cali, Colombia: Universidad del Valle.

Deavila, Orlando., y Guerrero, Lorena. (2011). Cartagena vista por los viajeros. Siglo XVIII-XX. Colombia: Universidad de Cartagena-Instituto Internacional de Estudios del Caribe, Alcaldía Mayor de Cartagena de Indias, Instituto de Patrimonio y Cultura de Cartagena.

El costurero de la SAC. (27 de abril de 1954). El Universal, p. 12.

Estadísticas de los últimos repartos. (19 de septiembre de 1954). Lumbre, p. 14. 
Federici, Silvia. (2013). Revolución en punto cero. Trabajo doméstico, reproducción y luchas feministas. Madrid, España: Traficantes de sueños.

Gallego, Beatriz. (2011). Una aproximación a la sociabilidad femenina y a la creación de la conciencia de género: los lavaderos en el mundo rural alavés. Euskonews. Recuperado de http://www.euskonews. eus/0578zbk/gaia57802es.html.

García, Lised. (2013). El barrio popular en Bogotá en las voces de sus protagonistas. Madres comunitarias y jardineras: 1989-2011, Usme y Ciudad Bolívar. Folios, (38), 121-140.

Garcés, Ángela. (2004). De-venir hombre mujer. Paso de la villa de la Candelaria a la ciudad de Medellín 19001940. Medellín, Colombia: Universidad de Medellín.

Grignon, Claude., y Passeron, Jean-Claude. (1991). Lo culto y lo popular. Miserabilismo y populismo en sociología y literatura. Buenos Aires, Argentina: Nueva Visión.

Harding, Sandra. (Ed.). (1987). ¿Existe un método feminista? En Sandra Harding (Ed). Feminism and Methodology (pp. 9-34). Bloomington-Indianapolis, EE.UU: Indiana University Press.

Las mujeres que trabajan. (05 de mayo de 1949). Lumbre, p. 13.

Londoño, Rocío., y Saldarriaga, Alberto. (1996). La ciudad de Dios. La caridad en Bogotá. Bogotá, Colombia: CINEP.

Luhmann, Niklas.. (2005). Organización y decisión. Autopoiesis, acción y entendimiento comunicativo. Barcelona, España: Anthropos Editorial.

Luna, Lola., y Villarreal, Norma. (1994). Movimientos de mujeres y participación política en Colombia del siglo XIX al siglo XX. Bogotá, Colombia: Gente Nueva.

Meertens, Donny. (2000). Ensayos sobre tierra, violencia y género. Bogotá, Colombia: Universidad Nacional de Colombia.

Mery, Fanny. (03 de marzo de 1918). Semimilo. Página Femenina. Correo Liberal, p. 3.

Nuevos atentados contra liberales en San Pelayo. (20 de julio de 1948). El Universal, p. 6.
Persecución a los conservadores. (13 de mayo de 1948). El Fígaro, p. 4.

Piñeres, Dora. (2008). Modernidad, universidad y región. El caso de la Universidad de Cartagena 19201946. Cartagena, Colombia: Editorial Universitaria.

Pitalua, Maico. (2014). Modernización y control social en Cartagena: los sujetos y las acciones sobre el problema de la vagancia, 1903-1927 (tesis de maestría). Universidad Andina Simón Bolívar, Quito, Ecuador.

Puyana, Yolanda. (2007). Los estudios de mujer y género en la Universidad Nacional. En Luz Gabriela Arango y Yolanda Puyana (Eds.), Género, mujeres y saberes en América Latina (pp. 115-151). Bogotá, Colombia: Universidad Nacional de Colombia.

Quejas de unos vecinos del barrio Rodríguez Torices. (15 de julio de 1954). El Universal, p. 6.

Redondo, Maruja. (2004). Cartagena de Indias. Cinco siglos de evolución urbanística. Bogotá, Colombia: Universidad Jorge Tadeo Lozano.

Se crea un problema social en los terrenos de Zaragocilla. (23 de julio de 1954). El Universal, p. 5.

Servicios para el barrio Daniel Lemaitre reclaman los vecinos. (21 de mayo de 1954). El Universal, p. 8.

Solano, Sergio. (1994). Empresarios y proyecto de modernización e imaginarios en la provincia de Cartagena durante la primera mitad del siglo XIX. Historia y Cultura, (3), 19-30.

Solano, Sergio., y Flórez, Roicer. (2011). Infancia de la nación. Colombia en el primer siglo de la república. Cartagena, Colombia: Ediciones Pluma de Mompox S.A.

Torres, Alfonso. (1999). Barrios populares e identidades colectivas. Serie Ciudad y Hábitat, (6). Recuperado de www.barriotaller.org.co/publicaciones/barrios_ populares.rtf.

Velásquez, Fabio. (1997). Ciudad y participación. Cali, Colombia: Editorial Universidad del Valle.

\section{Fuentes primarias}

Morelo, Josefa. Comunicación personal, 15 de mayo 2007. 